\title{
Invasive Intrasellar Plasmacytoma Mimicking Pituitary Adenoma
}

\author{
Tomohiro Terasaka ${ }^{1}$, Kenichi Inagaki ${ }^{2}$ and Fumio Otsuka ${ }^{1,3}$
}

Key words: bone fracture, pituitary tumor, plasmacytoma

(Intern Med 55: 1501-1502, 2016)

(DOI: 10.2169/internalmedicine.55.6414)
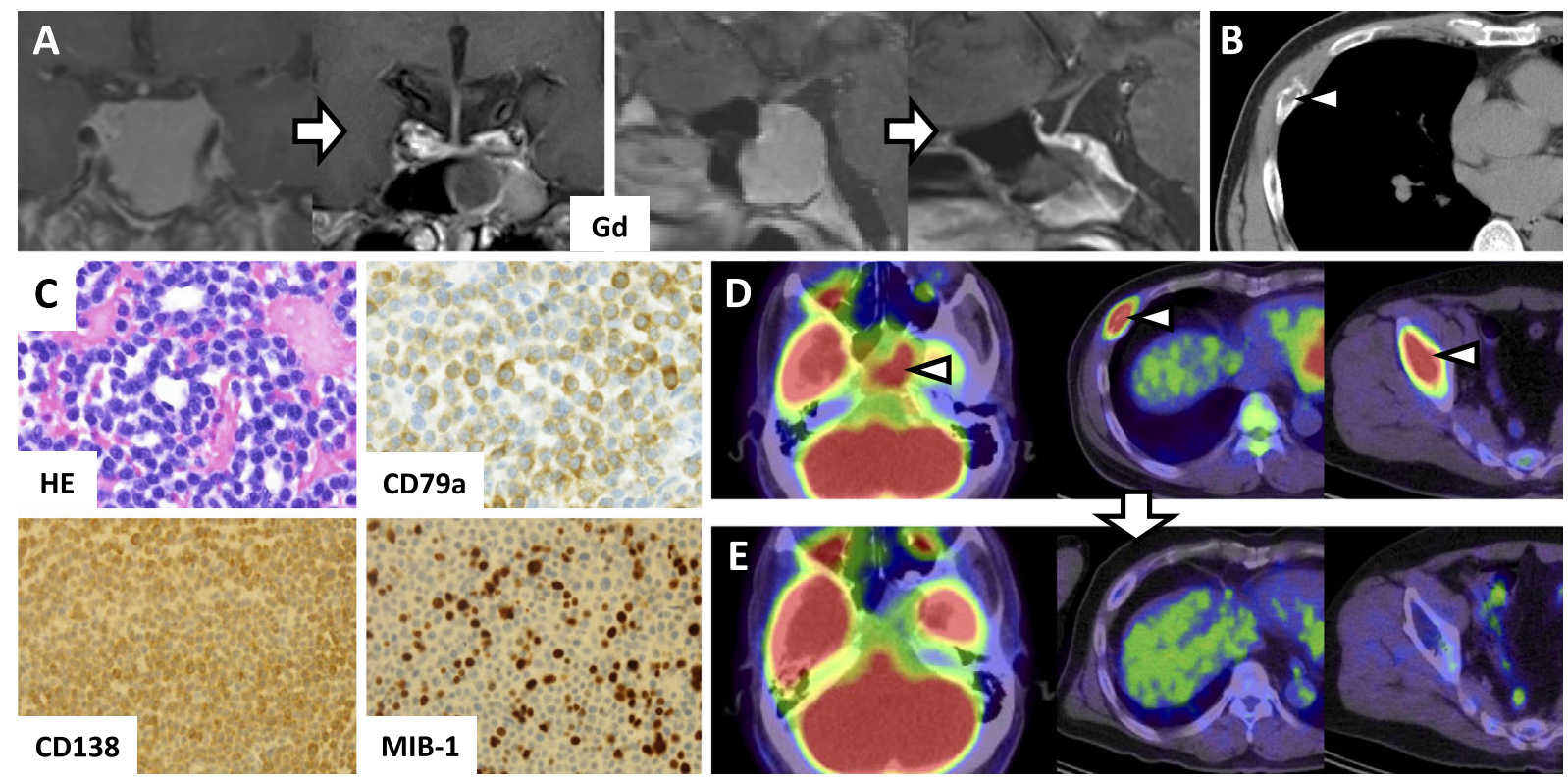

Picture.

Intrasellar plasmacytoma is a rare condition which is often misdiagnosed as pituitary adenoma. A 44-year-old man suffered from headache and diplopia. Pituitary MRI showed an invasive tumor involving the sphenoid sinus (Picture A). He had experienced costal fractures without trauma (Picture B) over the past few years. The patient's pituitary hormone levels were normal and $\mathrm{M}$ protein was not detected. The tumor was transsphenoidaly resected. A cyberknife was used to resect the residual tumor. High uptake was detected in the sellar mass, ribs and iliac bones by FDG-PET (Picture D). A CT-guided biopsy specimen of the bone and the resected pituitary tumor consisted of round cells, which expressed CD79a and CD138 (Picture C), leading to a diagnosis of plasmacytoma. The patient was treated with chemo- therapy with PBSCT. Follow-up examinations with MRI (Picture A) and FDG-PET (Picture E), which were performed five years after the patient's treatment, proved that it was effective. Thirty-two cases of intrasellar plasmacytoma have been reported to date (1). These cases are similar to invasive adenoma in that they are characterized by cranial nerve involvement and preserved anterior pituitary function (2). Systemic observation, which includes examinations to detect bone involvement is necessary for patients with pituitary disorders.

The authors state that they have no Conflict of Interest (COI).

\footnotetext{
${ }^{1}$ Laboratory Medicine, Okayama University Hospital, Japan, ${ }^{2}$ Endocrine Center, Okayama University Hospital, Japan and ${ }^{3}$ Department of General Medicine, Okayama University Graduate School of Medicine, Dentistry and Pharmaceutical Sciences, Japan

Received for publication August 19, 2015; Accepted for publication September 3, 2015

Correspondence to Dr. Fumio Otsuka, fumiotsu@md.okayama-u.ac.jp
} 
Intern Med 55: 1501-1502, 2016 DOI: 10.2169/internalmedicine.55.6414

\section{References}

1. Joukhadar R, Chiu K. Selllar plasmacytomas: a concise review. Pituitary 15: 146-149, 2012.
2. Sinnott BP, Hatipoglu B, Sarne DH. Intrasellar plasmacytoma presenting as a non-functional invasive pituitary macro-adenoma: case report \& literature review. Pituitary 9: 65-72, 2006.

(C) 2016 The Japanese Society of Internal Medicine http://www.naika.or.jp/imonline/index.html 